\title{
Genetic diversity and distance of Iranian goat breeds (Markhoz, Mahabadi and Lori) compared to the Beetal breed using inter-simple sequence repeat (ISSR) markers
}

\author{
Leila Simaei-Soltani ${ }^{1}$, Alireza Abdolmohammadi ${ }^{1}$, Alireza Zebarjadi ${ }^{2}$, and Saheb Foroutanifar ${ }^{1}$ \\ ${ }^{1}$ Department of Animal Science, Campus of Agriculture and Natural Resources, \\ Razi University, Kermanshah, Iran \\ ${ }^{2}$ Department of Agronomy and Plant Breeding, Campus of Agriculture and Natural Resources, \\ Razi University, Kermanshah, Iran
}

Correspondence to: Alireza Abdolmohammadi (alirezaam@razi.ac.ir)

Received: 20 August 2016 - Revised: 4 November 2016 - Accepted: 10 November 2016 - Published: 8 December 2016

\begin{abstract}
The aim of this study was to investigate the genetic diversity and structure in three Iranian native goat breeds (Markhoz, Mahabadi and Lori) and the Beetal imported breed using inter-simple sequence repeat (ISSR) markers and also to investigate ISSR markers' potential in order to genetically separate single (S) and twin-birth (T) subpopulations. Blood samples were collected from 210 animals for this purpose. In total, 16 primers were used, and finally 5 primers were selected based on the number of clear bands and the level of polymorphisms. The result of this study showed that 76 of 86 observed fragments were polymorphic. Genetic diversity for each breed ranged from 0.23 in the Beetal breed to 0.26 in the Markhoz breed; this represents a relatively similar genetic diversity in these breeds. An unweighted pair group method with arithmetic mean (UPGMA) dendrogram based on the Nei's standard genetic distance between the breeds studied showed that three Iranian goat breeds (Mahabadi, Lori and Markhoz) were clustered closer together, while the Beetal breed formed a separate cluster. In the constructed dendrogram of the subpopulations, the $\mathrm{S}$ and $\mathrm{T}$ subpopulations of each breed were clustered together. The constructed dendrogram of the Beetal breed and the $\mathrm{S}$ and $\mathrm{T}$ subpopulations of all breeds studied showed a separate cluster for the Beetal breed as an imported breed and another cluster for the $\mathrm{S}$ and $\mathrm{T}$ subpopulations as Iranian native breeds. The current study showed that the ISSR markers studied had no potential to genetically separate S and T subpopulations. On the other hand, these ISSR markers can be used for the clustering of distinct populations.
\end{abstract}

\section{Introduction}

Goats are probably one of the earliest ruminants domesticated around 10000 years ago (Zeder and Hesse, 2000). Today, goats are raised all over the world due to their tolerance to various environments, adaptability to nutrient-poor diets and manageable size. Goats are multipurpose animals that produce milk, meat and wool and contribute to the economy of farmers living in arid and semiarid regions, including south of Iran (Vahidi et al., 2014). The Iranian goat population is 21 million, which is $2.57 \%$ of the world's goat population (861.90 million) and $4.08 \%$ of the Asian goat population (514.4 million).
Genetic diversity is an essential component for population survival, evolution, genetic improvement and adaptation to changing environmental conditions (Kumar et al., 2009). The conservation of genetic variability has arisen in the last years because the existence of a large gene pool is important for the potential future breeding preservation and for sustainable animal production system development. Comprehensive knowledge of the existing genetic variability is the first step for the conservation and exploitation of domestic animal biodiversity.

Molecular tools permit us to characterize genetic resources at the DNA level. Inter-simple sequence repeat (ISSR) regions in the genome are currently useful markers for a wide 
Table 1. List of primers used for ISSR amplification and their annealing temperature.

\begin{tabular}{llc|llc}
\hline Primer & Sequences & $\begin{array}{c}\text { Annealing } \\
\text { temperature }\end{array}$ & Primer & Sequences & $\begin{array}{c}\text { Annealing } \\
\text { temperature }\end{array}$ \\
\hline $\mathrm{ISSR}_{1} \mathrm{C}$ & $(\mathrm{CA})_{8} \mathrm{G}$ & 55 & $\mathrm{ISSR}_{9}$ & $(\mathrm{GA})_{8} \mathrm{C}$ & 56 \\
$\mathrm{ISSR}_{2}$ & $(\mathrm{AG})_{8} \mathrm{~T}$ & 52 & $\mathrm{ISSR}_{10}$ & $\mathrm{G}(\mathrm{TC})_{8}$ & 54 \\
$\mathrm{ISSR}_{3}$ & $(\mathrm{ATG})_{6}$ & 47 & $\mathrm{ISSR}_{11}$ & $(\mathrm{TC})_{8} \mathrm{G}$ & 54 \\
$\mathrm{ISSR}_{4}$ & $(\mathrm{GATA})_{4}$ & 37 & $\mathrm{ISSR}_{12}$ & $(\mathrm{ACTG})_{4}$ & 50 \\
$\mathrm{ISSR}_{5}$ & $(\mathrm{AC})_{8} \mathrm{C}$ & 63 & $\mathrm{ISSR}_{13}$ & $(\mathrm{GAA})_{6}$ & 50 \\
$\mathrm{ISSR}_{6}$ & $(\mathrm{TC})_{8} \mathrm{~A}$ & 51 & $\mathrm{ISSR}_{14}$ & $(\mathrm{GACAC})_{4}$ & 52 \\
$\mathrm{ISSR}_{7}$ & $(\mathrm{AC})_{8} \mathrm{~T}$ & 52 & $\mathrm{ISSR}_{15}$ & $(\mathrm{GACA})_{4}$ & 53 \\
$\mathrm{ISSR}_{8}$ & $(\mathrm{GT})_{8} \mathrm{C}$ & 59 & $\mathrm{ISSR}_{16}$ & $(\mathrm{AG})_{8} \mathrm{TT}$ & 54 \\
\hline
\end{tabular}

range of molecular genetic studies such as establishing population structure, population differentiation and the reconstruction of phylogenetic relationships between populations, especially in plants (Wang et al., 2008). The ISSR markers are created using a single primer complementary to the microsatellite repeat (from 4 to 12 repeat units) and carrying the 3 ' sequence consisting of one or two arbitrary nucleotides (the so-called "anchor"). Such primers enable the amplification of the DNA fragments which are situated between two rather closely located inverted microsatellite sequences (Sulimova, 2004). The ISSR marker has a mild technical difficulty, good reproducibility and a reasonable cost, permitting its use for genetic studies of populations (Chen et al., 2005; Fagen and Nianhe, 2005)

The aim of this study was to investigate the genetic diversity and structure in three Iranian native goat breeds (Markhoz, Mahabadi and Lori) and the Beetal imported breed using ISSR markers and also to investigate ISSR markers' potential to separate single (S) and twin-birth (T) subpopulations genetically.

\section{Material and methods}

\subsection{Animals}

All protocols used in this study were approved by the Animal Care and Use Committee of Razi University. Blood samples were collected from a total of 210 individuals belonging to three Iranian native goat breeds and the Beetal imported breed: 60 Markhoz does (30 with an LS (litter size) of 1 and 30 with an LS of 2) from Sanandaj, 60 Mahabadi does (30 with an LS of 1 and 30 with an LS of 2) from Mahābād, 60 Lori does (30 with an LS of 1 and 30 with an LS of 2) from Lorestān and 30 Beetal does (LS > 2) as a control group from Sīstān va Balūchestān province.

\subsection{DNA extraction and polymerase chain reaction (PCR)}

DNA was extracted from whole blood using a DIAtom DNA Prep 100 kit (GenFanavaran Co, Iran). First, 16 ISSR primers were used, but 5 primers were selected due to the number of clear bands and polymorphic properties. Annealing temperature and sequences for all primers are listed in Table 1. Polymerase chain reaction was performed in a $15 \mu \mathrm{L}$ final volume containing 1 unit Taq DNA polymerase, $1.5 \mu \mathrm{L}$ of $10 \times$ PCR buffer, $0.2 \mathrm{mM}$ dNTPs, $0.25 \mu \mathrm{M}$ of primer, $25 \mathrm{mM}$ of $\mathrm{MgCl}_{2}$ and 50-100 ng of genomic DNA. PCR was carried out in an initial denaturation at $94^{\circ} \mathrm{C}$ for $3 \mathrm{~min}$, followed by 35 cycles of $30 \mathrm{~s}$ for denaturation at $94^{\circ} \mathrm{C}, 45 \mathrm{~s}$ for annealing at the temperature optimized for each primer (Table 1) and $90 \mathrm{~s}$ for extension at $72^{\circ} \mathrm{C}$, and a final extension step at $72^{\circ} \mathrm{C}$ for $7 \mathrm{~min}$. Then, $12 \mu \mathrm{L}$ of PCR products with $2 \mu \mathrm{L}$ of tracking dye was electrophoresed on a $1.2 \%$ non-denatured agarose gel and visualized over UV light after ethidium bromide staining to detect the amplification.

\subsection{Statistical analysis}

The measurement of diversity including gene diversity $(\mathrm{H})$, observed number of alleles $(\mathrm{Na})$, effective number of alleles $(\mathrm{Ne})$ and Shannon's information index was done by the POPGEN 1.31 software (Yeh et al., 1999). The software was also employed to determine Nei's unbiased genetic distances (Nei, 1978). A dendrogram based on Nei's unbiased genetic distances, using the unweighted pair group method with arithmetic mean (UPGMA), was generated to show the genetic distances of the populations or subpopulations investigated in this study.

\section{Results}

\subsection{Validation and polymorphism of ISSR primers}

In the current study, the repeatability of the PCR products was initially examined by the 16 primers on agarose gel for 21 samples. The test indicated that the patterns of ISSRs are polymorphic and reproducible in five primers including $(\mathrm{ATG})_{6},(\mathrm{AG})_{8} \mathrm{G},(\mathrm{GA})_{8} \mathrm{C},(\mathrm{AC})_{8} \mathrm{C}$ and $(\mathrm{TC})_{8} \mathrm{~A}$. Thus, these five primers were selected for ISSR-PCR analysis. In total, 86 fragments were observed from 210 DNA samples analyzed with five ISSR primers across four breeds; 
Table 2. Various measures of genetic variation at different loci across studied goat breeds.

\begin{tabular}{lrrrrrrrrr}
\hline Primer & $\begin{array}{r}\text { Sample } \\
\text { size }\end{array}$ & $\begin{array}{r}\text { Allele size } \\
(\mathrm{bp})\end{array}$ & $\mathrm{Na}$ & $\mathrm{Ne}$ & $\mathrm{H}$ & $\mathrm{I}$ & $\begin{array}{r}\text { No. of } \\
\text { scorable } \\
\text { bands }\end{array}$ & $\begin{array}{r}\text { No. of } \\
\text { polymorphic } \\
\text { bands }\end{array}$ & $\begin{array}{r}\text { Percentage of } \\
\text { polymorphic } \\
\text { bands }(\%)\end{array}$ \\
\hline$(\mathrm{ATG})_{6}$ & 210 & $520-2500$ & 1.89 & 1.47 & 0.28 & 0.43 & 19 & 17 & 89.47 \\
$(\mathrm{AG})_{8} \mathrm{G}$ & 210 & $300-2300$ & 1.94 & 1.37 & 0.23 & 0.36 & 17 & 16 & 94.12 \\
$(\mathrm{GA})_{8} \mathrm{C}$ & 210 & $280-2600$ & 1.83 & 1.43 & 0.25 & 0.38 & 18 & 15 & 83.33 \\
$(\mathrm{AC})_{8} \mathrm{C}$ & 210 & $280-2000$ & 1.89 & 1.46 & 0.26 & 0.40 & 18 & 16 & 88.89 \\
$(\mathrm{TC})_{8} \mathrm{~A}$ & 210 & $400-2000$ & 1.86 & 1.54 & 0.31 & 0.46 & 14 & 12 & 85.71 \\
\hline Overall & & & 1.88 & 1.45 & 0.27 & 0.41 & 86 & 76 & 88.37 \\
$\mathrm{SD}$ & & 0.32 & 0.36 & 0.18 & 0.25 & & & \\
\hline
\end{tabular}

Na: observed number of alleles; Ne: effective number of alleles; H: Nei's genetic diversity; I: Shannon's information index.

Table 3. Various measures of genetic variability among different goat breeds.

\begin{tabular}{lrrrrr}
\hline \multicolumn{1}{c}{$\begin{array}{r}\text { Sample } \\
\text { Population }\end{array}$} & size & $\mathrm{Na}$ & $\mathrm{Ne}$ & $\mathrm{H}$ & $\mathrm{I}$ \\
\hline Mahabadi & 60 & $1.77 \pm 0.43$ & $1.41 \pm 0.36$ & $0.24 \pm 0.19$ & $0.37 \pm 0.26$ \\
Lori & 60 & $1.78 \pm 0.42$ & $1.40 \pm 0.36$ & $0.24 \pm 0.19$ & $0.36 \pm 0.26$ \\
Markhoz & 60 & $1.80 \pm 0.40$ & $1.46 \pm 0.38$ & $0.26 \pm 0.19$ & $0.39 \pm 0.27$ \\
Beetal & 30 & $1.71 \pm 0.46$ & $1.40 \pm 0.38$ & $0.23 \pm 0.20$ & $0.35 \pm 0.28$ \\
\hline Overall & 210 & $1.88 \pm 0.32$ & $1.45 \pm 0.36$ & $0.27 \pm 0.18$ & $0.41 \pm 0.25$ \\
\hline $\begin{array}{l}\text { Na: observed number of alleles; Ne: effective number of alleles; H: Nei's genetic diversity; I: Shannon's } \\
\text { information index. }\end{array}$
\end{tabular}

76 fragments $(88.37 \%)$ were polymorphic (Table 2$)$. The average observed number of alleles per locus ranged from 1.83 $\left((\mathrm{GA})_{8} \mathrm{C}\right)$ to $1.94\left((\mathrm{AG})_{8} \mathrm{G}\right)$, with a mean value of 1.88 . Relevant information per locus, such as the range of allele sizes, effective number of alleles (Ne), Nei's genetic diversity $(\mathrm{H})$, Shannon's information index (I), number of scorable bands, number of polymorphic bands and percentage of polymorphic bands (\%), are presented in Table 2.

\subsection{Genetic heterozygosity criteria in Iranian goat breeds}

The genetic characterization of the studied goat breads is shown in Table 3. Among the breeds, the mean number of alleles ranged from 1.71 in Beetal to 1.80 in the Markhoz breed. Nei's gene diversity and Shannon's information index were relatively similar in the breeds studied (Table 3). It seemed that the breeds studied have relatively similar genetic diversity. Among the breeds, total heterozygosity $(\mathrm{Ht})$, the average heterozygosity within populations $(\mathrm{Hs})$ and diversity between the four populations (Dst) were 0.26, 0.25 and 0.01 , respectively. The average genetic differentiation coefficient (Gst) value (Weir and Cockerham, 1984), another measure of genetic differentiation, over all loci was 0.056 indicating that $5.6 \%$ of total genetic variation corresponded to differences between populations, whereas $94.4 \%$ was explained by differences between individuals.
Table 4. Nei's (1978) genetic identity (I, above diagonal) and genetic distance (D, below diagonal) among the four goat breeds.

\begin{tabular}{lrrrr}
\hline Breeds & Mahabadi & Lori & Beetal & Markhoz \\
\hline Mahabadi & - & 0.9868 & 0.9740 & 0.9789 \\
Lori & 0.0133 & - & 0.9746 & 0.9764 \\
Beetal & 0.0264 & 0.0258 & - & 0.9771 \\
Markhoz & 0.0213 & 0.0238 & 0.0231 & - \\
\hline
\end{tabular}

\subsection{Genetic distance of the goat populations studied}

The results of the estimated Nei's unbiased measures of genetic distances (Nei, 1978) for the breeds studied are presented in Table 4. According to this, the highest genetic distance between the breeds was 0.0264 , which indicates a high genetic similarity between the breeds studied. A cluster analysis based on Nei's standard distance matrix (Nei, 1978) (Table 4; Fig. 1) showed two main groups: one consisting of the three Iranian goat breeds, which exhibited the Mahabadi and Lori breeds in one cluster, followed by Markhoz, and the other consisting of the Beetal breed. Nei's genetic distance between the $\mathrm{S}$ and $\mathrm{T}$ subpopulations of the breeds studied is shown in Table 5. Although the genetic distance between all subpopulations is low, this value between the $\mathrm{S}$ and $\mathrm{T}$ subpopulations of each breed is less than that of different breeds. 
Table 5. Nei's (1978) genetic identity (I, above diagonal) and genetic distance (D, below diagonal) between single (S) and twin-birth (T) subpopulations of goat breeds.

\begin{tabular}{lrrrrrrr}
\hline Populations & S Mahabadi & T Mahabadi & S Lori & T Lori & Beetal & S Markhoz & T Markhoz \\
\hline S Mahabadi & - & 0.9942 & 0.9849 & 0.9881 & 0.9775 & 0.9794 & 0.9794 \\
T Mahabadi & 0.0058 & - & 0.9789 & 0.9818 & 0.9624 & 0.9702 & 0.9701 \\
S Lori & 0.0152 & 0.0213 & - & 0.9937 & 0.9722 & 0.9701 & 0.9726 \\
T Lori & 0.0120 & 0.0184 & 0.0064 & - & 0.9734 & 0.9745 & 0.9732 \\
Beetal & 0.0228 & 0.0383 & 0.0282 & 0.0270 & - & 0.9723 & 0.9791 \\
S Markhoz & 0.0208 & 0.0302 & 0.0304 & 0.0258 & 0.0281 & - & 0.9933 \\
T Markhoz & 0.0209 & 0.0304 & 0.0278 & 0.0271 & 0.0211 & 0.0067 & - \\
\hline
\end{tabular}

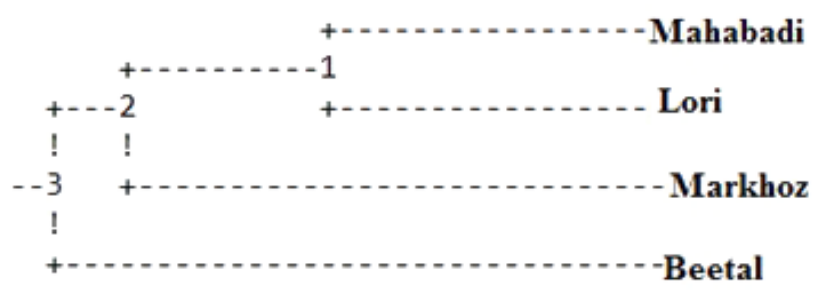

Figure 1. The phylogenetic dendrogram showing the genetic relationships between goat populations using the Nei (1978) standard genetic distance obtained from five ISSR markers.

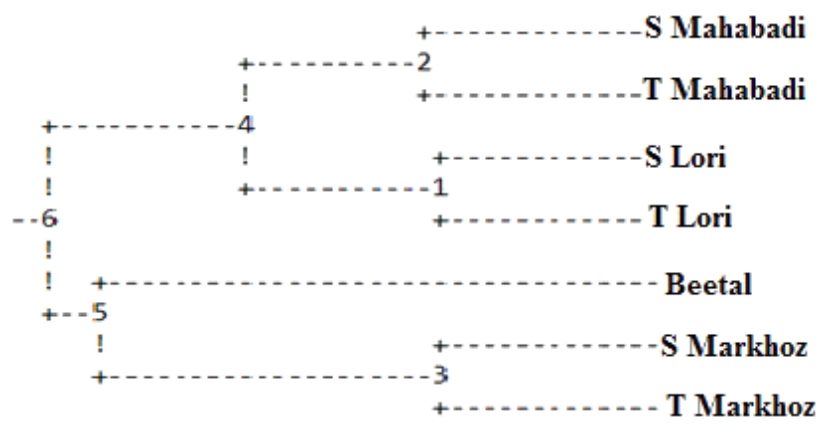

Figure 2. The phylogenetic dendrogram showing the genetic relationships between the single $(\mathrm{S})$ and twin-birth $(\mathrm{T})$ subpopulations of the goat breeds studied using the Nei (1978) standard genetic distance obtained from five ISSR markers.

\subsection{Genetic distance of single (S) and twin-birth (T) subpopulations}

The phylogenetic dendrogram of the $\mathrm{S}$ and $\mathrm{T}$ subpopulations of the breeds studied based on Nei's genetic distance analysis (Fig. 2) placed the $\mathrm{S}$ and $\mathrm{T}$ subpopulations of each breed in one cluster, and, overall, they were divided into two groups: one includes S Mahabadi and T Mahabadi in one branch with S Lori and T Lori subpopulations. Another consists of Beetal and then the S Markhoz and T Markhoz subpopulations.

Nei's (1978) genetic identity and genetic distance between the Beetal breed and the $\mathrm{S}$ and $\mathrm{T}$ populations of the other breeds studied are shown in Table 6 . According to this, the
Table 6. Nei's (1978) genetic identity (I, above diagonal) and genetic distance $(\mathrm{D}$, below diagonal) between the Beetal breed and the single (S) and twin-birth (T) subpopulations of the other breeds studied.

\begin{tabular}{lrrr}
\hline Populations & S populations & T populations & Beetal \\
\hline S populations & - & 0.9988 & 0.9809 \\
T population & 0.0016 & - & 0.9817 \\
Beetal & 0.0193 & 0.0184 & - \\
\hline
\end{tabular}

$\mathrm{S}$ and $\mathrm{T}$ populations are closer together and have a greater distance to the Beetal breed. The phylogenetic relationship between the Beetal breed and the $\mathrm{S}$ and $\mathrm{T}$ populations of the other breeds studied was constructed on the basis of Nei's standard distance matrix (Nei, 1978) (Fig. 3). As seen in Fig. 3, the $\mathrm{S}$ and $\mathrm{T}$ populations were grouped in one cluster and the Beetal breed in another one.

\section{Discussion}

Genetic variation is a basic requirement for animal breeding, whereas high genetic variation is needed for the genetic improvement of domestic animals (Askari et al., 2011). The analysis of genetic diversity is a method to estimate the variation present in populations (Weir, 1990). Therefore, we used ISSR markers to assess genetic variation based on the mean allelic frequency of the 86 ISSR fragments obtained in the breeds studied. The total number of alleles per locus in the present study ranged from 14 to 19 . The higher number of alleles for each locus showed that all the markers used were appropriate to analyze diversity in the breeds studied.

Genetic diversity for each breed ranged from 0.23 in Beetal to 0.26 in Markhoz. The measures of genetic variation in the present study indicated a moderate level (0.27) of Nei's genetic diversity in the four goat breeds studied. No significant differences in the genetic diversity were observed within populations, and they had a relatively similar genetic diversity. This result was in accordance with those of Italian goat populations (Ajmone-Marsan et al., 2001), Moxoto goat breed (Oliveira et al., 2005) and six Iranian indigenous goat 


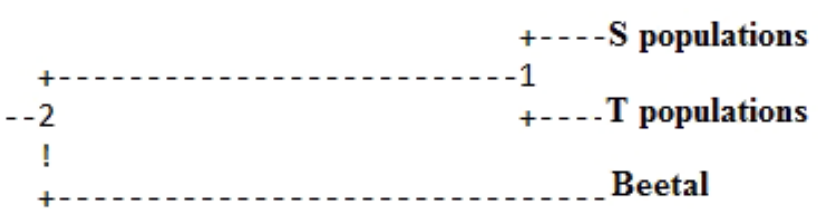

Figure 3. The phylogenetic dendrogram showing the genetic relationships between the Beetal breed and the $\mathrm{S}$ and $\mathrm{T}$ populations of the other breeds studied using the Nei (1978) standard genetic distance obtained from five ISSR markers.

populations (Mirhoseini and Badrbarin, 2013). The genetic diversity in this study was higher than that of some Iranian breeds (Askari et al., 2011; Zamani et al., 2011), and Najdi, Harri and Aradi Saudi goat breeds (Sabir et al., 2013); however, the diversity was noticeably lower than that of Korean and Chinese goats (Kim et al., 2002), twelve Chinese indigenous goat populations ( $\mathrm{Li}$ et al., 2002), southern Italian goat populations (Iamartino et al., 2005), Egyptian and Italian goat breeds (Agha et al., 2008), and Indian goat breeds (Dixit et al., 2012) and was also slightly lower in comparison to the color types of the Markhoz goat populations (Moradii et al., 2014). Zamani et al. (2011), Askari et al. (2011) and Moradii et al. (2014) used two ISSR markers for their studies; the sequence of ISSR markers in their studies was also different from those in the present study. Sabir et al. (2013) used 30 goats in their study, which is much lower than the sample size in our study (210 goats); also, the sequence of some ISSR markers in their study was different from those in the present study. On the other hand, Kim et al. (2002), Li et al. (2002), Imartino et al. (2005), Agha et al. (2008) and Dixit et al. (2012) used microsatellite markers in their studies. Thus, the differences in genetic diversity values obtained could be due to the type of markers used, the sequence of ISSR markers, sampling and sample size.

The Shannon information index was 0.41 , indicating that $41 \%$ of effective alleles (a mean of 1.44 alleles per locus) were on average identified per primer. Our estimate of the Shannon information index was in accordance with what is reported by Moradii et al. (2014) on the color types of Markhoz goat populations and by Mirhoseini and Badbarin (2013) on six Iranian indigenous goat populations. This estimated index was higher than that for Mehraban sheep (Zamani et al., 2011), Rayini goats (Askari et al., 2011), and Najdi, Harri and Aradi Saudi goat breeds (Sabir et al., 2013). However, the Shannon information index in this study was lower than that of Kermani sheep (Esfandyarpour et al., 2008).

An overall mean of Gst $=5.6 \%$ (based on five markers) indicated that within-breed diversity accounts for a large part of the total genetic diversity of the breeds investigated. This value was similar to those found in the Najdi, Harri and Aradi Saudi goat breeds (5.9\%) (Sabir et al., 2013), domestic Capra hircus breeds reared within an early goat domes- tication area in Iran (5.9\%) (Vahidi et al., 2014), and European and Middle Eastern goats (6.9\%) (Canon et al., 2006) but lower than the values reported for Italian goat populations $(7.3 \%)$ (Iamartino et al., 2005), six Iranian indigenous goat populations ( $8 \%$ ) (Mirhoseini and Badbarin, 2013), the color types of Markhoz goat populations (9\%) (Moradii et al., 2014), south-east Asian goats (14\%) (Barker et al., 2001) and Indian goat breeds (16.2\%) (Dixit et al., 2012)

The phylogenetic dendrogram of the breeds (Fig. 1) showed that the Mahabadi and Lori breeds were grouped together, with the Markhoz breed deviating from them. This type of clustering was completely consistent with the fact that Markhoz is a Mohair-producing breed but Mahabadi and Lori are known as meat and milk-producing breeds. Furthermore, the Beetal breed formed a separate cluster from Iranian goats. It is noteworthy that this breed has been recently imported from Pakistan into Sīstān va Balūchestān province in Iran. Therefore, this observed difference can be due to geographical distance, which is exacerbated by the official borders between the two countries. Similar population clustering according to geographic location was previously observed in 12 Chinese indigenous goat breeds ( $\mathrm{Li}$ et al., 2008, 2002), Egyptian and Italian goat breeds (Agha et al., 2008), Indian goat breeds (Dixit et al., 2012), and 6 Iranian indigenous goat populations (Mirhoseini and Badbarin, 2013).

In the dendrogram constructed of the subpopulations of the breeds studied (Fig. 2), the $S$ and $T$ subpopulations per breed were grouped in the same cluster. In fact, the ISSR markers used in this study showed a low potential for separating the $S$ and $\mathrm{T}$ subpopulations as different clusters. The ISSR markers amplify intergenic and non-coding regions of the genome, and these regions may not have any effect on the number of kids (twining trait). It seems that a study on major genes known for the twining trait can distinguish $\mathrm{S}$ subpopulations from T subpopulations. For example, Rasouli et al. (2016) reported that the twinning rate in Markhoz goats was significantly influenced by the IGF-I and IGFBP-3 genotypes; also, the association of two single nucleotide polymorphisms (SNPs) in the growth hormone (GH) gene with the litter size and superovulation response in goat breeds has been studied, and the results have shown that the two loci of the GH gene are highly associated with abundant prolificacy and a superovulation response in goat breeds (Zhang et al., 2011).

The phylogenetic tree constructed between the Beetal breed and the $\mathrm{S}$ and $\mathrm{T}$ subpopulations for all the breeds studied (Fig. 3) showed a separate cluster for the Beetal breed as an imported breed and another cluster for the $\mathrm{S}$ and $\mathrm{T}$ subpopulations as Iranian native breeds. This finding confirmed that geographic distance and different agroclimatic conditions and probably breeding objectives have an important effect on genetic diversity.

Moradii et al. (2014) showed that the phylogenetic dendrogram of color types using ISSR markers was in agreement with their phenotypic similarities, in which saddle brown and sandy brown color types were grouped in one cluster and 
black types in another one. However, the current study is the first report using ISSR marker analysis to investigate the possibility of different clustering for the twining trait in several goat populations (Agha et al., 2008; Dixit et al., 2012; Javanrouh Aliabad et al., 2004; Li et al., 2008; Mirhoseini and Badbarin, 2013).

However, the low number of ISSR markers (five markers) and the sample size ( 30 goats per subpopulation) in the current study may be other reasons for the low potential of the ISSR markers studied to show $\mathrm{S}$ and $\mathrm{T}$ subpopulations in different clusters. It seems that this would be clearer using many more ISSR markers in larger goat populations.

In conclusion, this study has shown the moderate genetic diversity in some native goat breeds. This research has also shown that the ISSR markers studied had no potential to genetically separate $\mathrm{S}$ and $\mathrm{T}$ subpopulations, while ISSR markers can be used to cluster distinct populations.

\section{Data availability}

The original data of the paper will be available upon request to the corresponding author.

Author contributions. A. Abdolmohammadi and S. Foroutanifar designed this project, L. Simaei Soltani carried it out and wrote the paper, and A. Zebarjadi helped us in the molecular analysis of ISSR markers.

Competing interests. The authors declare that they have no conflict of interest.

Acknowledgements. We would like to thank to H. M. Moradi Shahr Babak and M. Khaldari for help in collecting blood samples and also Razi University for financially supporting this project.

Edited by: S. Maak

Reviewed by: T. Gruszecki and two anonymous referees

\section{References}

Agha, S., Pilla, F., Galal, S., Shaat, I., D'andrea, M., Reale, S., Abdelsalam, A., and Li, M.: Genetic diversity in Egyptian and Italian goat breeds measured with microsatellite polymorphism, J. Anim. Breed. Genet., 125, 194-200, 2008.

Ajmone-Marsan, P., Negrini, R., Crepaldi, P., Milanesi, E., Gorni, C., Valentini, A., and Cicogna, M.: Assessing genetic diversity in Italian goat populations using AFLP ${ }^{\circledR}$ markers, Anim. Genet., 32, 281-288, 2001.

Askari, N., Abadi, M. M., and Baghizadeh, A.: ISSR markers for assessing DNA polymorphism and genetic characterization of cattle, goat and sheep populations, Iran. J. Biotechnol., 9, 222-229, 2011.
Barker, J. S. F., Tan, S. G., Moore, S. S., Mukherjee, T. K., Matheson, J., and Selvaraj, O.: Genetic variation within and relationships among populations of Asian goats (Capra hircus), J. Anim. Breed. Genet., 118, 213-234, 2001.

Canon, J., Garcia, D., García-Atance, M., Obexer-Ruff, G., Lenstra, J., Ajmone-Marsan, P., and Dunner, S.: Geographical partitioning of goat diversity in Europe and the Middle East, Anim. Genet., 37, 327-334, 2006.

Chen, J., Liu, X., Gituru, W., Wang, J., and Wang, Q.: Genetic variation within the endangered quillwort Isotoma petraea (Lobeliaceae), Mol. Ecol., 8, 775-789, 2005.

Dixit, S., Verma, N., Aggarwal, R., Vyas, M., Rana, J., and Sharma, A.: Genetic diversity and relationship among Indian goat breeds based on microsatellite markers, Small. Rum. Res., 105, 38-45, 2012.

Esfandyarpour, E., Askari, N., Mohammad-Abadi, M., Nowshari, A., Asadi-Moghadam, R., Asadi-Fori, M., Esmaeilizade, A., and Baghizade, A.: Use of inter-simple sequence repeat (ISSR) markers to evaluate genetic diversity of Kermani sheep, 3rd Congress on Animal Science, University of Ferdowsi, Iran, 22 September, 2008.

Fagen, L. and Nianhe, X.: Population structure and genetic diversity of an endangered species, Glyptostrobus pensilis (Cupressaceae), Bot. Bull. Acad. Sinica, 46, 155-162, 2005.

Iamartino, D., Bruzzone, A., Lanza, A., Blasi, M., and Pilla, F.: Genetic diversity of Southern Italian goat populations assessed by microsatellite markers, Small. Rum. Res., 57, 249-255, 2005.

Javanrouh Aliabad, A., Esmaeelkhanian, S., Dinparast, N., and Vaez Torshizi, R.: Genetic variation among six Iranian goat breeds using RAPD markers, Pajuhesh Sazandegi, 12-17, 2004.

Kim, K., Yeo, J., Lee, J., Kim, J., and Choi, C.: Genetic diversity of goats from Korea and China using microsatellite analysis, Asian. Australas, J. Anim. Sci., 15, 461-465, 2002.

Kumar, S., Dixit, S., Verma, N., Singh, D., Pande, A., Chander, R., and Singh, L.: Genetic diversity analysis of the Gohilwari breed of Indian goat (Capra hircus) using microsatellite markers, Am. J. Anim. Vet. Sci., 4, 49-57, 2009.

Li, J., Chen, H., Lan, X., Kong, X., and Min, L.: Genetic diversity of five Chinese goat breeds assessed by microsatellite markers, Czech J. Anim. Sci., 53, 315-319, 2008.

Li, M.-H., Zhao, S.-H., Bian, C., Wang, H.-S., Wei, H., Liu, B., Yu, M., Fan, B., Chen, S.-L., and Zhu, M.-J.: Genetic relationships among twelve Chinese indigenous goat populations based on microsatellite analysis, Genet. Sel. Evol., 34, 729-744, 2002.

Mirhoseini, S. Z. and Badbarin, N.: Assessing genetic diversity in six Iranian indigenous goat populations using AFLP markers, J. Food Agric. Environ., 11, 495-497, 2013.

Moradii, M.-H., Rostamzadeh, J., Rashidi, A., Vahabi, K., and Farahmand, H.: Analysis of genetic diversity in Iranian mohair goat and its color types using Inter Simple Sequence Repeat (ISSR) markers, Agric. Commun., 2, 55-62, 2014.

Nei, M.: Estimation of average heterozygosity and genetic distance from a small number of individuals, Genetics, 89, 583-590, 1978.

Oliveira, R. R. D., Egito, A. A. D., Ribeiro, M. N., Paiva, S. R., Albuquerque, M. D. S. M., Castro, S. R., Mariante, A. D. S., and Adrião, M.: Genetic characterization of the Moxotó goat breed using RAPD markers, Pesq. Agropec. Bras., 40, 233-239, 2005. 
Rasouli, S., Abdolmohammadi, A. R., Zebarjadi, A. R., and Mostafaei, A.: Evaluation of polymorphism in IGF-I and IGFBP3 genes and their relationship with twining rate and growth traits in Markhoz goats, Ann. Anim. Sci., doi:10.1515/aoas2016-0020, online first, 2016.

Sabir, J. S., Sabry, A. M., Awad, N. S., Mohamed, A. A., and Mutawakil, M. H.: Najdi, Harri and Aradi Saudi goat breeds possess genetic variation required for genetic improvement, World Appl. Sci. J., 26, 867-872, 2013.

Sulimova, G.: DNA Markers in Genetic Studies: Types of Markers, Their Properties and the Range of Application, Usp. Sovrem. Biol., 124, 260-271, 2004.

Vahidi, S. M. F., Tarang, A. R., Naqvi, A. U. N., Falahati Anbaran, M., Boettcher, P., Joost, S., Colli, L., Garcia, J. F., and AjmoneMarsan, P.: Investigation of the genetic diversity of domestic Capra hircus breeds reared within an early goat domestication area in Iran, Genet. Sel. Evol., 46, 1-12, doi:10.1186/1297-968646-27, 2014.

Wang, X., Zhao, F., Hu, Z., Critchley, A. T., Morrell, S. L., and Duan, D.: Inter-simple sequence repeat (ISSR) analysis of genetic variation of Chondrus crispus populations from North Atlantic, Aquat. Bot., 88, 154-159, 2008.
Weir, B. S.: Genetic data analysis, Methods for discrete population genetic data, Sinauer Associates, Inc. Publishers, 376 pp., 1990.

Weir, B. S. and Cockerham, C. C.: Estimating F-statistics for the analysis of population structure, Evolution, 38, 1358-1370, 1984.

Yeh, F., Yang, R., and Boyle, T.: Microsoft Windows-based freeware for population genetic analysis, Release 1.31, University of Alberta, Edmonton, 1999.

Zamani, P., Akhondi, M., Mohammadabadi, M. R., Saki, A. A., Ershadi, A., Banabazi, M. H., and Abdolmohammadi, A. R.: Genetic variation of Mehraban sheep using two intersimple sequence repeat (ISSR) markers, Afr. J. Biotechnol., 10, 18121817, 2011.

Zeder, M. A. and Hesse, B.: The initial domestication of goats (Capra hircus) in the Zagros Mountains 10,000 years ago, Science, 287, 2254-2257, 2000.

Zhang, C., Liu, Y., Huang, K., Zeng, W., Xu, D., Wen, Q., and Yang, L.: The association of two single nucleotide polymorphisms (SNPs) in growth hormone (GH) gene with litter size and superovulation response in goat-breeds, Genet. Mol. Biol., 34, 49-55, 2011. 